\title{
Mood Propensity as a Constituent of Happiness: A Rejoinder to Hill
}

\author{
Daniel M. Haybron
}

Published online: 4 June 2008

(C) Springer Science+Business Media B.V. 2008

\begin{abstract}
In an earlier paper I defended an emotional state theory of happiness. In a basic form, emotional state theories identify happiness with a person's moods and emotions. To this formulation I added a second component, "mood propensity": roughly, an individual's disposition to experience moods, which can vary with the circumstances. Scott Hill argues that this view is vulnerable to a serious counterexample and that my intuitive arguments for it are unconvincing. This paper extends my earlier defense of mood propensity as an aspect of happiness, in the process replying to Hill's objections. I argue that the intuitive considerations favoring my view are not weakened by the points Hill raises. Moreover, the inclusion of dispositional elements in a theory of happiness is actually quite common, and there are good substantive, and not just intuitive, reasons for incorporating mood propensity in the account. In particular, it seems to be required by the guiding conception of happiness as a matter of a person's overall emotional condition.
\end{abstract}

Keywords Happiness - Mood · Emotional state · Affect · Emotion · Well-being $\cdot$ Life satisfaction · Hedonism · Philosophy $\cdot$ Welfare

\section{Introduction}

In "On Being Happy or Unhappy" (henceforth OBH) I outlined and defended an emotional state conception of happiness as an alternative to the dominant accounts, hedonistic and life satisfaction theories (2005). Emotional state theories of happiness can take various forms, but the version I defended includes a less-than-obvious component, "mood propensity"- -very roughly, the individual's disposition to experience certain moods rather than others, which can vary with the circumstances of an individual's life. The claim is significant for several reasons, one being that it may form part of a plausible account of well-being. (Haybron 2005, 2008a, b. Note that this is not a trivial claim, since 'happiness' in this debate serves as a purely descriptive psychological term and not a synonym for

D. M. Haybron ( $\square)$

Department of Philosophy, Saint Louis University, St. Louis, MO 63103, USA

e-mail: haybrond@slu.edu 
'well-being' or 'eudaimonia'. ${ }^{1}$ To establish a view of happiness thus leaves it open whether happiness plays any fundamental role in well-being. Tortured artists, e.g., may not consider happiness important for well-being.)

For empirical investigators, the mood propensity view suggests that predominant "feeling-based" measures of experienced affect in subjective well-being research may be inadequate, assessing only a part of happiness. Someone good at repressing distress might be cheerful most of the time even though, at some deeper level, her emotional condition might be substantially unfavorable. To get at such information, new measures such as mood induction tests may be needed. E.g., highly stressed professionals might present as being in a positive mood during testing yet respond strongly to negative mood inductions, such as frustrating tasks. (Some investigators have already employed such instruments, with provocative results. See, e.g., Shedler and Mayman et al. 1993.)

However, the inclusion of mood propensities in an account of happiness is controversial, and even proponents of emotional state theories might doubt whether this aspect of my view is warranted. Scott Hill argues in some detail for a negative verdict (Hill 2007). I am grateful for Hill's thoughtful and extensive discussion of my work, and to the editor of this journal for the opportunity to reply. In what follows I will defend the inclusion of mood propensities in my account, responding first to the particular concerns raised by Hill. The remainder of the paper will further elaborate the rationale for incorporating mood propensities, arguing that such a move is both plausible and well-motivated (a more extensive treatment, touching on some but not all of the points made here, appears in Haybron 2008b). However, we may in the final analysis want to revise the notion of mood propensity or replace it altogether with some related notion. The key point is that we recognize a constituent of our emotional conditions, and in turn happiness, that is psychologically deeper than a mood or emotion, yet more variable than a trait.

Let me begin with a brief recap of the emotional state theory. Driving this approach is the intuitive idea of happiness - and, by extension, unhappiness - as a matter of a person's overall emotional condition, or emotional state. I cash this out in terms of two basic types of state: first, a person's “central” (vs. peripheral) affective states-roughly, canonical moods and emotions, as opposed to mere physical sensations of pain or pleasure (think orgasm), or trivial affects like mild amusement or annoyance. So far the view differs from hedonism in excluding such "peripheral" pleasures from happiness and, most importantly, incorporating moods and emotions in their entirety (whereas the hedonist counts only the pleasantness or unpleasantness of these states, leaving out unconscious, dispositional, or physiological aspects). The second component is an individual's propensity to experience certain central affective states rather than others: her "mood propensity" (though strictly she will possess multiple mood propensities at any given time). I suggested that this twopart schema is plausible, not just for an account of happiness, but for accounts of related phenomena like depression: depression, the condition, is not naturally thought of as a particular mood. It is rather a syndrome, or a condition, consisting of characteristic moods and emotions (notably, depressed moods) along with an underlying tendency or propensity toward such moods and emotions. Happiness, I suggested, is essentially a positive counterpart to, among other things, depression. Contra the hedonist, one is intuitively unhappy

\footnotetext{
1 As a psychological matter, happiness is amenable to scientific study and measurement, a point I discuss in Haybron (2008b). Our subject matter should also be distinguished from the particular emotion or mood of feeling happy, as well as the trait of having a happy personality. Assessments of happiness concern not a specific feeling but the individual's overall psychological condition in some respect. While usually assessed over extended periods, e.g., "nowadays," happiness can be defined over arbitrarily brief periods of time.
} 
by virtue of being depressed - not by virtue of experiencing the unpleasantness of depression. The emotional state theory accords happiness greater psychological depth than hedonism, at least as that view is usually understood.

Hill's objection in his paper concerns the second part of my theory, mood propensities. His discussion divides into two major parts: first, a set of arguments meant to undercut three examples I gave in support of mood propensities (as a fundamental constituent of happiness-I will usually omit the qualifier); and second, an extended counterexample in which my account ostensibly gives the wrong answer to whether an individual is happy. I believe Hill's strongest challenge to my view concerns the three examples, but I want to respond to the counterexample before addressing it.

\section{Replies to Hill's Objections}

\subsection{The Very Phobic Dennis*}

I confess that I may not have taken in all the details of this most elaborate example. But if I understand it correctly, the idea is that Dennis* was happy at a convention despite having a putatively negative mood propensity. This he has by virtue of his powerful aversion to various kinds of things-avocados, horses, martial artists, etc.- that happen to be present at the convention. And his negative mood propensity is said to be emotionally-based because his presence at the convention was caused by the occurrence of various bad feelings shortly beforehand. Intuitively, Dennis* is happy at the convention, since his emotions and moods are positive. Yet according to my account, as Hill reads it, he must not be happy. Therefore, my account must be false: by including mood propensity as a component of happiness, it suffers from a fatal counterexample. If Hill is right, we at least have an important datum that counts against my view.

But I don't believe this is a genuine counterexample, as the view it problematizes is not mine. At a number of points Hill considers various aspects of my account and restates them in more precise terms, generally in claims of the form " $P$ if and only if $Q$ ". The attempt to state formally what I put informally is admirable, but I don't believe any of the proposed reformulations are equivalent to the views stated in my paper. (For the most part, I think my discussion was clear enough for the purposes at hand. The trouble is that any effort to restate a philosophical claim in more precise terms can raise difficulties owing not to the view itself, but to the formulation. Thus we can end up arguing about our formulas rather than the issueswhich I fear has happened in this case. Hence there is good reason to state claims only as precisely as the dialectical situation requires, keeping debate focused on the relevant issues.)

Here, I want to note a point about Hill's statement of my basic view (p. 8). My claim is that happiness is partly constituted by an individual's mood propensity. I do not claim that a positive mood propensity is necessary for being happy; nor do I believe that it is. (Elsewhere I distinguish between "fragile" and "robust" forms of happiness, the fragileand less pronounced-form of happiness involving a "negative mood [propensity]" (Haybron 2001a, 2008b). I left the distinction out of the target article for reasons of space.) So even granting that Dennis* has a negative mood propensity in the relevant sense, I could perfectly well accept the intuition that he is happy. What I would have to say is that Dennis*'s happiness is diminished by virtue of any negative mood propensities. But this falls short of saying that he isn't happy.

The main question, however, is whether Dennis* really has negative mood propensities in the relevant sense. The account of happiness is meant to track an intuitive understanding 
of a person's emotional condition. The vagueness of "mood propensity" is reined in somewhat via a pair of qualifications. The first is that mood propensity is "generalized: it involves a tendency to experience positive moods quite generally" (Haybron 2005, p. 306). The fact, say, that your dog tends to lift your mood speaks (in itself) to your attitude or feelings toward your dog, not your emotional condition. Such "object-specific" dispositions regarding particular objects, or kinds of objects, thus don't count. This requirement is not an ad hoc stipulation thrown in to ward off counterexamples: it is demanded by the guiding conception of happiness as a matter of one's emotional condition, as opposed to one's attitudes toward things. Hill takes Dennis* to circumvent this requirement because his phobias are manifold, so that there are multiple kinds of objects in his environment that could trigger a meltdown: his negative mood propensity is thus not object-specific.

The simple reply, it seems to me, is to say that Dennis*'s mood propensities are, clearly, object-specific in the relevant sense, or more to the point aren't generalized. Plainly, Dennis*'s emotional condition is not affected at all by his attendance at the convention. For the negative dispositions he has reflect, not his emotional condition, but his aversions or attitudes regarding avocados, horses and the like. I might have forestalled this sort of objection by extending the "dog" example and emphasizing that even a propensity to feel good in the company of one's dog or one's motorcycle (etc...) would not be generalized; but it seems to me that was not necessary to add.

Moreover, it is odd to think that Dennis*'s emotional disposition should have changed at all by going to the convention; what changed is not his disposition, but the presence of triggers. The change of environment changed the likelihood of a meltdown, but not his disposition to fall apart in certain conditions. Similarly, salt does not become more or less water-soluble depending on the amount of water nearby.

Here's an example to illustrate the sort of thing I had in mind when formulating the notion of mood propensity: imagine that humans are equipped with psychological mechanisms dedicated to regulating our moods — "thymostats," if you will (Haybron 2001a, p. 202). My discussion of a person's "hair-trigger propensity for anxiety" could be understood in terms of her anxiety thymostat being set to high sensitivity: whatever inputs the "anxiety system" is sensitive to, it will be highly sensitive to. Whereas, in happier times, the individual's anxiety thymostat is dialed down to low sensitivity, so that it takes a lot to trigger anxiety. Now this little picture is doubtless oversimplified in various ways, and I do not claim that the relevant mood propensities must be grounded in any such mechanism. The point is to gesture at what I had in mind when characterizing mood propensities as generalized: this sort of mechanism could be almost completely insensitive to content. This is utterly different from having strong attitudes toward certain sorts of items, of which my dog case is one example and Hill's Dennis* case is another. I had assumed that readers would form a similar picture in light of the various examples I provided, but probably should have been more explicit about it. (Though I do say something similar in a footnote in OBH where I discuss dynamical systems approaches to moods, suggesting that we might think of mood propensities as given by the shape of an individual's mood state space (p. 306). The hair-trigger propensity for anxiety, e.g., will be represented as an attractor within this space in the region of anxiety.)

I suspect the culprit is Hill's earlier attempt to formalize the notion of mood propensity, in particular the idea that a mood propensity obtains when "there are a wide variety of common and likely events" that would trigger an emotional response if they occurred (p. 7). This is itself vague, but it goes beyond anything I explicitly claim, and it is not clear why I must be committed to it. At any rate, Hill's discussion of Dennis* seems to fix on an interpretation of this formula on which his mood propensity does change on entering the convention: for there may indeed be a sense in which there are now "a wide variety of 
common and likely events" that could set Dennis* off. But at this point we are twice removed from my discussion of mood propensity - an interpretation of an interpretation of my account-and have arrived at something other than the view I defended.

The second qualification to the notion of mood propensity is that it be "emotionallybased": it should reflect one's emotional condition. Specifically, what I said was that the categorical basis of one's mood propensity must be (some aspect of) one's emotional condition. Thinking again in terms of a simplified boxology, we might imagine that people have an "emotion system" that generates the affective component of moods and emotions. And to have a mood propensity - to extend the previous story-is for one or more of the emotion system's thymostats to be set a certain way. The categorical basis for the mood propensity, then, is the setting of the thymostats: that's what grounds the disposition. Whereas one might alternatively be prone to anxiety (say) not because of anything to do with the configuration of the mood system, but simply because of some recurrent stimulus, unmediated by any thymostats, as in the toe-pain case (Haybron 2005, pp. 306-7). But on no understanding of categorical basis, as far as I know, is what causes your propensity thereby its categorical basis. What grounds Dennis*'s propensity to melt down is not the feelings of sadness etc. that caused him to end up at the convention, but rather something like an attitude toward avocados and such. The features of the causal chain leading up to his propensity are simply irrelevant to the question of what grounds that propensity. Dennis*'s negative propensity might perhaps be emotionally caused-assuming, that is, that his propensity for a meltdown indeed altered when he entered the convention-but it is not emotionally-based.

Note also that I do not require the categorical bases of mood propensities to be central affective states, as Hill suggests (p. 16). While dispositionality may be necessary for something to be a central affective state, it is not sufficient. Since the introduction of mood propensities is motivated substantially by the idea happiness involves something deeper than central affective states, it would be odd if they were wholly grounded in central affective states.

\subsection{The Three Cases Taken to Favor Mood Propensities}

The most significant worries for my view are raised earlier in Hill's paper. Hill claims that three cases, which he calls A, B and C-supplying his own names for the characters-are employed to "motivate the inclusion of mood propensity" in my account of happiness (p. 7). This is partly true: I do take them to provide intuitive support for my view, but I do not believe that such intuitions alone suffice to make the case. An important part of my argument, not discussed by Hill, draws not on intuitions about particular cases but on broader theoretical considerations. I will return to those later. Why does he think these examples fail to support my view? He thinks they are underdescribed: once we fill in the details a bit more, our intuitions no longer seem to support my claims. Consider case B, involving laughter at a funeral: Hill objects that "in a normal case, a subject that laughs at a funeral is still overwhelmingly sad and upset" (p. 9). So we might indeed think someone laughing at a funeral is nonetheless unhappy, but the reason has nothing to do with his mood propensity; it lies wholly in his continuing to experience negative affects like sadness and upset. If the example seemed to support my account, that is only because I left those details out of the story. Hill argues that similar problems afflict the other two cases. Case A involves a stressed graduate student, called Alice by Hill, whose happiness is said to be compromised by a pronounced propensity toward anxiety. Case $\mathrm{C}$, finally, has friends 
Cliff and Clyde (originally Tom and Jerry) on vacation, where both experience generally positive moods, slightly more so in Clyde's case. Yet Clyde, coming off a recent divorce, occasionally breaks down in tears for no obvious reason. If we have intuitions of compromised happiness in these cases, Hill objects, it is because we imagine the individuals actually experiencing negative emotions and moods.

Let me say, first, that Hill has indeed identified a potential vulnerability of my argument, one shared I think by any appeal to intuitions: alternative explanations of our intuitions are always possible, and Hill aptly points out how the alternative possibilities might go. But these examples were never intended to supply bulletproof evidence of the mood propensity claim, and the possibility of alternative explanations always looms when milking examples for intuitions. (As well, it is almost certain that some readers will not share the intuitions, the hope being that these are not too numerous, and that most such disagreement can be chalked up to some kind of error. Hill does suggest that we may not have the intuitions if we were to imagine the cases correctly, but does little more than raise it as a possibility, which indeed it is. His critique focuses on finding alternative explanations for the intuitions rather than denying them.) The more interesting question is whether my reading of the cases is more plausible than the alternatives. I believe that it is.

The first thing to note is that, if you are voluntarily imagining the cases as Hill suggests, then you aren't playing the game correctly. For both cases A and C, I stipulated that the individuals are not experiencing the relevant affects. Only in case B did I leave that point unspecified, since it was obvious enough how I intended the reader to fill in the blanksviz., with Ben not feeling overwhelmingly sad and upset. (It would be a very poor example otherwise! ${ }^{2}$ ) What I envisioned was a situation where the individual, while laughing, really is having a pleasant experience; the laughter is genuine and heartfelt. If we want to say that the individual's emotional condition at such times is not particularly positive, we arguably need to look below the surface. What I suggested is that, intuitively, the problem lies not with the person's occurrent affects, which seem largely to be positive, but at an unconscious level, with his basic emotional disposition. The survivor having a pleasant moment at the funeral is not entirely happy at that moment, not because he feels sad, but because his present good cheer is so fragile and prone to yield to grief. I did not spell this out in detail, in part because it can be useful to leave some particulars to the reader's imagination, since each reader brings a different background to the table, and may find a different variant of the case most compelling. Since the question is whether there are any cases that support my account, the reader needs to try to picture the example in a way that makes sense given that aim. If the reader can't picture the case in a way that yields the desired result, or if unwanted factors unconsciously influence her intuitions, then my argument has a genuine problem.

If Hill's objection is to raise genuine doubts about my arguments, it presumably must amount to this: that we can't picture the cases in the intended manner (e.g., with Ben not feeling sad and upset); or, alternatively, that what drives our intuitions is a reflexive tendency to posit occurrent emotions (e.g., of sadness and upset). If either of these things happens consciously, then we ought to be aware that we aren't thinking about the cases correctly. This often happens with exotic cases where we find it hard even to imagine the scenario clearly. But Hill does not claim this to be the problem, and for my own part these

\footnotetext{
${ }^{2}$ In fairness, my example was stated as an overbroad generalization to keep it short: "When we attend a funeral reception and see grieving family members laughing..." This is a little misleading, as it encompasses a variety of cases, not all of which would serve my purposes. I trust that any philosopher could easily discern which cases I had in mind, but should have been more careful in ruling out the "laughing but feeling sad" cases explicitly.
} 
cases do not seem at all hard to envision (with the possible exception of case C). I expect that the problem, if there is one, must be unconscious: while we seem to have intuitions favoring mood propensities (or some unconscious states in that neighborhood), those intuitions are actually driven by a tacit—and apparently incorrigible-assumption that the individuals are having occurrent affects (e.g., of sadness and upset).

Is this plausible? It is certainly possible, hence in great part my admission that these examples are not conclusive. But surely it is less straightforward, and less plausible, than simply taking the appearances at face value: if it seems to you that (e.g.) Ben's happiness is compromised even when he isn't feeling sad or upset, this could be because you nonetheless assume, unconsciously, that he is sad and upset. But what reason do we have to think that our unconscious is actually frustrating our efforts this way?

Hill's response, I believe, would be that this is more than a mere possibility: it is in fact the most plausible explanation, for normally people don't simply have negative mood propensities in cases like these - they actually experience the negative moods and emotions. (At every moment?) Regarding case B, for instance, Hill claims that "in a normal case, a subject that laughs at a funeral is still overwhelmingly sad and upset" (p. 9). We are thus conditioned to think of people that way, and this expectation is what explains our intuitions about compromised happiness. ${ }^{3}$ A similar thought likely accounts for the assurance with which Hill dismisses the original description of case C; he argues that, insofar as we take Clyde's tears to signify a deficit in happiness, this is simply because we conclude that his moods during the vacation weren't so good after all: the tears are evidence "that he has been in quiet anguish over the divorce for the entirety of the trip" (p. 10)—despite my stipulation to the contrary. I take the reasoning behind this move to be that my description of the case is so far outside the norm that we cannot help but insert the quiet anguish. ${ }^{4}$

Now I don't stake much confidence in my ability to say what "normal" cases in this realm are like, but I would have thought there are many normal ways to feel in situations such as these. In the case of a funeral, for instance, it depends on your personality, your

\footnotetext{
${ }^{3}$ I am grateful to an anonymous referee for pressing this objection. Regarding case A, an interesting suggestion was made that people who are prone to anxiety typically experience "meta-anxiety," anxiety about becoming anxious, and that we assume individuals are in this state even when not anxious about anything in particular, and likewise for the other cases. While an intriguing thought, this seems to me just another way of saying that the individual is anxious, contrary to the example. As well, it does not seem to me likely that people normally do have such states, still less so that we typically assume as much. In fact I would question how often people even know enough about their anxiety to have meta-states about it. I suspect people are often fairly oblivious to their own moods (Haybron 2007a, 2008b).

4 Hill goes on to acknowledge my stipulations about Clyde's state, suggesting that if we take those on board then the intuition evaporates: Clyde indeed seems happier than Cliff. But this seems to amount to saying that readers will only have the intuition if they seriously misread the example, ignoring my stipulations. But if dispelling the intuition is simply a matter of reading the case correctly, then it makes no sense to speak of intuition favoring my analysis at all. Perhaps Hill really means to deny the intuition outright, but the appearance is that he grants it some putative force, wanting instead to explain it away. It seems to me more plausible, and more consistent with his broader strategy, to read Hill as taking the example to be hard to envision without contamination by our expectations about normal cases-whereas if we were to do so successfully, we would not have the intuition. While better, this reading leaves us with a claim that is hard to evaluate: if our intuitions are contaminated even when we think they are not, how can we tell what they would be when they really aren't contaminated? Note as well that Hill revises my argument in two ways that might lend his contention unwarranted credence. First, Hill's language stacks the deck in favor of his conclusion: given the general description of the case, I'm not sure it's at all natural to think of Clyde's state, as Hill does, in terms like "tranquil," "exuberant," and "joyful." These terms are naturally associated, not merely with being happy, but with the heights of happiness. Second, Hill's rendering of the case focuses on how Cliff would most likely regard Clyde, yet that question was peripheral to my argument, which centered on what seems plausible to $u s$, being privy to facts about Clyde's state that Cliff would not ordinarily know.
} 
relationship with the person, the nature of the death, etc. Likewise following a divorce, or while finishing a dissertation. (It bears remarking that intuitions about how it is normal to feel in a given situation, say after a tenure denial or being crippled in an accident, are notoriously unreliable. ${ }^{5}$ ) In any event, whatever "normal" cases are like, surely none of these cases is particularly exotic or bizarre, and indeed they seem to me to represent perfectly ordinary, commonplace occurrences. This is why my descriptions of the cases tended to be so brief: I trusted the reader, who likely has encountered similar cases in the past, would have little difficulty seeing what I was getting at. So I do not see why it should be difficult to envision these examples as intended. Hill, of course, might respond in kind, arguing that by his lights these cases truly are bizarre, or at least far enough outside the norm that our intuitions most likely reflect a tacit assumption of occurrent feelings rather than unconscious states like mood propensities. If so the argument, being stalemated, would have to turn to other points. Elsewhere I have noted further intuitive considerations favoring my account, but here I will rest with the examples at hand, and the substantive arguments noted below (Haybron 2008b).

Before concluding my discussion of the intuitive arguments, I want to note a crucial gap in Hill's critique: it does not address the central claim made in case A, as well as a similar claim made for case C. Hill revises case A by bringing in a counterpart, Alice*, whose dissertation is going better. If I understand Hill correctly, the idea is to compare Alice with an otherwise identical individual whose mood propensity is more positive: is she really intuitively less happy than Alice*? Insofar as I am able to picture the scenario, which is difficult, the answer seems to me "yes," but at any rate Hill has us looking at the wrong intuitions. The original case explicitly referred to an intuition about the impact of her propensity for anxiety on her happiness: "Wouldn't you consider her less happy by virtue of that fact, quite apart from the anxious moods themselves?" (p. 305). It is conceivable that even this intuition results entirely from an inference that she must actually be experiencing a lot of anxiety and is therefore less happy. But it is not likely. Similarly, my argument regarding case $\mathrm{C}$ appeals directly to an intuition about the impact of Clyde's propensity for sadness on his happiness.

Perhaps it will be objected that appeals to "metaphysical" intuitions like these are illegitimate: we may have solid intuitions about whether someone is happy or not, but we have no such intuitions about why-by virtue of what-she is happy. But of course we do have such intuitions, and many philosophical theories suffer precisely because they seem to many to get their answers - correct answers or not-for the wrong reason. Smart consequentialists who want to handle common intuitions about justice, for instance, know that it isn't enough merely to accommodate intuitions that it's wrong to murder a healthy individual so you can save a greater number of lives with his organs. For we also have intuitions about what makes it wrong: not that it wouldn't after all yield the best consequences—yuck—but that it violates the individual's rights, or some kindred reason. Those intuitions are widespread and powerful, and consequentialism faces serious trouble unless it can defuse them, for instance by explaining why it makes good consequentialist sense to have such intuitions. Similarly, at least some of us have intuitions about the constitution of happiness, and insofar as people do have them, a good theory of happiness ought, ideally, to have some means of addressing them.

Summing up: I do not think these cases were problematically underdescribed in $\mathrm{OBH}$, as Hill contends. Insofar as I left some details unspecified, it is easy enough for the reader to supply them, thus imagining the cases as intended. In two of the cases, moreover, my

${ }^{5}$ See, e.g., Gilbert 2006. 
argument appealed directly to intuitions about the impact of a given state on the individual's happiness, so that no further details could be needed. Hill's real challenge is to point out that insofar as we do have the intuitions, it could be because we are tacitly assuming various claims about the occurrent moods and emotions in play. So I cannot rule out alternative explanations of the intuitions regarding these cases. The more interesting question is whether Hill's alternative hypotheses are at least as plausible as mine. This I don't see: none of these cases is particularly exotic or difficult to imagine, so why must our unconscious frustrate our attempts to think about them clearly? Suppose you find it intuitive that Alice's happiness is compromised by a sharp propensity to anxiety, even when she isn't anxious. It is possible that you believe this only because, apparently unconsciously, you can't help imagining her anxious. But this explanation for the intuition is obviously more complicated; barring further reason for thinking it not just possible but true, we should favor the simpler reading of the case.

\section{The Substantive Case for Mood Propensities}

I now want to focus on more substantive points, explaining why, beyond satisfying some intuitions, it makes sense for an account of happiness to incorporate mood propensities. I begin by noting a surprising claim Hill makes about the theoretical landscape, namely that my view is more or less unique in according a dispositional element to happiness (p. 1). In fact, there have traditionally been two broad approaches to happiness, and one of them arguably takes happiness to be largely dispositional, more so in fact than my own account does. I am referring here to life satisfaction theories of happiness, which identify happiness roughly with having a favorable attitude toward one's life as a whole.

On the most natural and compelling reading of this notion, to be satisfied with one's life is not, in the first instance, to be having any kind of experience or any other occurrent mental state. Life satisfaction is an attitude, more akin to what is sometimes called a "dispositional" belief, and might best be analyzed in dispositional terms: to be satisfied with one's life, e.g., just $i$, at least in part, to be disposed to think about one's life in certain ways, to have certain feelings when contemplating one's life, and so forth. (See, e.g., Benditt 1974, 1978. For dispositionality in the examples Hill cites, see Tatarkiewicz 1976, p. 10; and Sumner 1996, p. 146, where he implicitly takes "being disposed to think that your life is going well" to be part of happiness.)

There are good reasons to go dispositional, owing to our distinctive concern with life satisfaction attitudes: they can seem to embody an important evaluation of the agent's life. Is her life going well enough by her standards? The significance of such an evaluation does not depend on its being an occurrent mental state. It can seem important that Nora is disappointed with her life, and the significance of this disappointment does not diminish if, at the present moment, she's having no thoughts about her life at all. What we seem to care about here, fundamentally, is where the agent stands regarding her life: does she approve of it? Is she favorably disposed toward it? Life satisfaction need not be a wholly occurrent conscious state to have this kind of significance, and in fact its significance depends on its not being required that the individual have some occurrent thought or feeling about her life at every moment (for further discussion, see Haybron 2007b, 2008b). Indeed, the only credible alternative to incorporating dispositions is to identify the attitude with something like a representation stored in long-term memory-but this itself is not an occurrent or conscious state, and in fact resembles the "unconscious mood" alternative to mood propensities noted below. 
Life satisfaction theories take happiness to be substantially or even wholly a cognitive or rational evaluation of the agent's life, this being a major attraction: they can seem to suit our status as rational animals with priorities that we care about. Now you might like the basic strategy of viewing happiness as a matter of the agent's basic orientation or disposition toward his life, how he stands regarding his life, but doubt that life satisfaction is really the best way to think about it. You might think happiness more an emotional evaluation of one's life-how the agent is disposed emotionally regarding his life. On this approach, happiness embodies the verdict of the psyche, or emotional self. (I often find 'psyche' more congenial in this context, as other terms like 'emotional' or 'mood' have misleading connotations.) Happiness, then, is a kind of psychic or emotional "thumbs-up": call it psychic affirmation (Haybron 2008b). Whereas unhappiness represents a kind of psychic "thumbs-down" in response to one's life. When depressed, for instance, it is not just that you are having an extremely unpleasant experience: more than this, it is that your psyche is essentially registering extreme disapproval of your life. Sometimes you might enjoy good moods when depressed, say at the peak of your daily mood cycle, or when at a party. But you remain depressed, and not happy, throughout, because your fundamental psychic orientation remains substantially negative-as becomes clear when the party is over or the good mood otherwise gives way, again, to the depths.

The view I am talking about, of course, is the emotional state theory of happiness. And while I originally defended the theory as a response to defects with hedonism, it is closer in important respects to life satisfaction views, precisely in its concern with the individual's basic psychological disposition regarding her life. We can think of it as a sentimentalist rival to the life satisfaction view's rationalism. ${ }^{6}$ So my view, far from being strange and recherché, sits squarely in the philosophical mainstream. If we avoid focusing too narrowly on hedonism, and keep in mind that life satisfaction theories take happiness to be chiefly a dispositional matter, then my account should not seem odd at all. The alleged oddness of mood propensities, then, is likely to depend on whether you take hedonism or life satisfaction as your baseline view for comparison. (Compare as well our interest in health, which we often discuss in parallel with happiness, as in "healthy and happy." It too fundamentally concerns the individual's disposition, so that we don't consider someone healthy who has a large plaque that is liable at any moment to break off and cause a fatal coronary or stroke.)

Incorporating mood propensities, moreover, arguably brings the account into line with popular views of the unconscious. It would be perfectly natural, for instance, for a thinker in the psychoanalytic tradition to reject the idea of happiness as purely a matter of occurrent, conscious mental states. Arguably, the substantially unconscious character of unhappiness is what has largely paid their bills. (They seem not to have had much to say about happiness as a positive phenomenon, it being in their eyes neither profitable nor, apparently, a real occurrence. Recall Freud's stated goal of converting "hysterical misery" into "common unhappiness"- - happiness evidently being too much to hope for (Freud and Breuer 1895, p. 306). Would he have been persuaded otherwise by the compelling evidence that most people actually experience a majority of positive affect (Diener and Diener 1996)? Or would he observe that this is only a part of the story?)

Those of a psychoanalytic bent would likely have no difficulty granting the essentials of my descriptions of the various cases (A, B, and $\mathrm{C}$ )—viz., that the individuals in question

\footnotetext{
${ }^{6}$ Of course, life satisfaction is naturally regarded as partly emotional as well, but the most compelling versions of such a view tend to emphasize high-level global judgments that are tied closely to the individual's rational commitments.
} 
are not entirely happy, and this at least partly by virtue of nonconscious states. Indeed, I suspect many of them would regard such cases as utterly typical. It seems a virtue of my account, then, that it accords with this important strain of thought about our emotional lives. $^{7}$

Note that ideas linking happiness to the unconscious are not isolated to fans of Freudian psychology. They appear to be pervasive in contemporary folk psychology. It is a perfectly ordinary thought, if not a cliché, that someone might be generally in a good mood yet not be happy because, down in the boiler room, all is not well-as is revealed when the individual suddenly explodes or breaks down. Unconsciously, something is awry, yet only at certain moments do we get a glimpse. This of course is the stuff of many fictions. Similarly, we all go through periods of greater and lesser fragility regarding our emotional states, and being particularly fragile is frequently taken to preclude, or at least speak against, the ascription of happiness.

It should be clear that the emotional state theory is not wildly revisionary or eccentric. Neither is it ad hoc or unmotivated: the inclusion of mood propensity in the theory is not simply driven by intuitions about three examples. It is required by the basic rationale of the theory: to conceive of happiness as a matter of a person's overall emotional condition. To be happy is to be responding, emotionally, in a favorable way to one's life. And if our mood propensities really do vary with the conditions of our lives as I have suggested, then surely we should admit that those propensities_or something in the vicinity-form part of our emotional response to our lives. We should count them as part of our emotional conditions, and hence, on an emotional state view, as part of happiness.

Look at it this way: suppose we take the first step and abandon hedonism for some sort of emotional state theory, taking happiness to consist in an individual's emotions or moods in their entirety. Once we've taken that step, what could the rationale be for stopping there and not including something like mood propensities? If your unhappiness consists partly in your irritable mood's disposing you to lash out over trivial matters, then why don't other aspects of your emotional disposition count? Hedonists have a good answer to these questions: they don't think dispositional properties count at all. Indeed, the only aspect of our emotional lives that directly speaks to our happiness is their hedonic aspect-how pleasant the experiential aspects of our emotions are. This is well-motivated, since we have a distinctive set of concerns relating to the hedonic quality of our experience. (Though, as I argue elsewhere, these concerns differ from those driving our interest in happiness. See Haybron 2001b, 2005, 2008b.) Once you abandon the hedonistic rationale for your theory by embracing an emotional state view, you need a way to decide which states count and which don't. On the emotional state theory with mood propensities, we can appeal to the basic ideal of happiness as a matter of emotional condition, embodying the individual's emotional response to her life. This rationale is not available to "simple" emotional state theories, and so such views appear, barring some alternative story, to be unmotivated.

Incorporating mood propensities may have another point in its favor: elsewhere I have argued for a view of well-being in which happiness plays a central role (Haybron 2008a, b). The reason well-being consists centrally in happiness is that happiness, on the

\footnotetext{
7 Two qualifications are needed, however. First, I am not certain whether Freud and others in this tradition regarded happiness and unhappiness as (partly) constituted by unconscious states, or simply as caused by them. It is possible to grant the importance of the unconscious for happiness without thinking that happiness just $i s$, in part, a matter of unconscious states. Second, the notion of mood propensity itself does not, as far as I know, figure directly in the psychoanalytic literature. It may be more natural, from a psychoanalytic perspective, to think in terms of unconscious states and processes which may not be wholly reducible to dispositions. This suggests a possible modification of my view, which I will turn to in a moment.
} 
emotional state view, is closely tied to the self: very roughly, who one is depends partly on what ways of living tend to make one happy. Well-being in turn is viewed as a matter of self-fulfillment, in a manner reminiscent of ancient eudaimonism, and so the theory of well-being is parasitic on our conception of the self. This connection between happiness and the self hinges on the psychological depth of happiness, to which mood propensities add considerably. If this view is correct, then conceiving of happiness partly in terms of mood propensities yields dividends for our understanding of well-being and the self.

Given that the emotional state theory defended in OBH is grounded in a plausible ideal, and given that it yields connections between happiness and the self that may determine the character of well-being, we have good reason to think this view well-motivated. It has more going for it than simple intuitive appeal. So even if Hill's arguments weaken the intuitive case for my view_which I don't believe they do-there is still much to recommend it.

\section{From Mood Propensity to Unconscious Moods?}

My account of happiness is not intended to be a finished product, and it would be disappointing indeed if we could not eventually come up with a more exact characterization of happiness. In light of the preceding discussion of the unconscious, here is one possible modification to the emotional state theory: perhaps the notion of mood propensity should be replaced by some concept of unconscious mood or emotion. We could thus say that Alice's propensity for anxiety is grounded in a state of unconscious anxiety, so that even when in a relaxed mood she remains, at some deeper level, anxious, and her happiness is diminished by virtue of this unconscious anxiety. Not just anxious in a way that eludes introspection, notice, but anxious in a way that doesn't turn up at all in her typical behaviors, thoughts, or feelings. It is completely subterranean, serving purely to trigger states of garden-variety anxiety when the occasion calls for it. (Contrast this with an ordinary mood that might, at a given moment, have no impact on one's consciousness. Irritability is a good example-sometimes it seems to have no experiential aspect at all. Note that this differs from a propensity to become irritable. Sometimes you aren't in an irritable mood at all, yet you are still emotionally fragile, so that a chain of annoyances might be more likely than usual to make you become irritable.)

I know of no reason why emotional states couldn't be like this- "occurrent," in the strict sense that they involve active processing, but not occurrent in the colloquial sense of being conscious or otherwise part of the agent's "outward" mental life. I gather that Freud himself refused to countenance unconscious emotions, but there seems no reason why the basic psychoanalytic schema couldn't be applied this way. And if we do admit unconscious moods and emotions in this way, it may be possible to eliminate reference to "mood propensity" in the theory, perhaps extending the class of central affective states to include such unconscious states.

Whether this is a good idea will depend on several factors: whether such states really exist, whether we can plausibly take them to constitute the categorical basis of emotionally-based mood propensities, and whether, having identified the categorical basis of these propensities, we should really take happiness to consist in that, and not in the propensities themselves. (I originally did focus on the categorical bases, using "mood base" instead of "mood propensity" (Haybron 2001a, 2001b). This may have been the right strategy all along, but I switched to the "propensity" formulation to make the view more easily grasped, and because our ascriptions of happiness seem to be driven by the propensities and not so much by reference to their hidden categorical bases.) 
I do not know how all this will turn out, so I will stick with the existing formulation in terms of mood propensities. But offhand, I am doubtful that unconscious moods can do all the needed work: if, e.g., there are analogues to thymostats, then these too, it seems to me, should inform the account, for they too would partly define an individual's emotional condition. And beyond thymostats and unconscious moods, our emotional conditions may incorporate other states or mechanisms that regulate mood. We are operating here with a kindergarten psychology, with probably only the faintest notion of the affective life of the animal were are dealing with. Until we get a better handle on the phenomena, it seems reasonable to stick with the simple formulation of happiness in terms of mood propensity.

\section{References}

Benditt, T. M. (1974). Happiness. Philosophical Studies, 25, 1-20.

Benditt, T. M. (1978). Happiness and satisfaction - a rejoinder to Carson. The Personalist, 59, $108-109$.

Diener, E., \& Diener, C. (1996). Most people are happy. Psychological Science, 7(3), 181-185.

Freud, S., \& Breuer, J. (1895). Studies in hysteria. New York: Penguin Books.

Gilbert, D. (2006). Stumbling on happiness. New York: Knopf.

Haybron, D. M. (2001a). Happiness and ethical inquiry: An essay in the psychology of well-being. Ph.D. Dissertation, Rutgers University.

Haybron, D. M. (2001b). Happiness and pleasure. Philosophy and Phenomenological Research, 62(3), 501-528.

Haybron, D. M. (2005). On being happy or unhappy. Philosophy and Phenomenological Research, 71(2), 287-317.

Haybron, D. M. (2007a). Do we know how happy we are? Nous, 41(3), 394-428.

Haybron, D. M. (2007b). Life satisfaction, ethical reflection and the science of happiness. The Journal of Happiness Studies, 8, 99-138.

Haybron, D. M. (2008a). Happiness, the self, and human flourishing. Utilitas, 20(1), 21-49.

Haybron, D. M. (2008b). The pursuit of unhappiness: The elusive psychology of well-being. New York: Oxford University Press.

Hill, S. (2007). Haybron on mood propensity and happiness. The Journal of Happiness Studies. doi: 10.1007/s10902-007-9076-Z

Shedler, J., Mayman, M., et al. (1993). The illusion of mental health. American Psychologist, 48(11), 1117-1131.

Sumner, L. W. (1996). Welfare, happiness, and ethics. New York: Oxford.

Tatarkiewicz, W. (1976). Analysis of happiness. The Hague: Martinus Nijhoff. 